\title{
METABOLIC AND CARDIOVASCULAR PROFILE IN TYPE 2 DIABETES MELLITUS PATIENTS UNDERGOING DIFFERENT TREATMENT MODALITIES
}

\author{
Shruthi Suvarna H. I', Shailaja Moodithaya², Raghava Sharma³ , Amrit M. Mirajkar4 \\ ${ }_{1}^{1}$ Lecturer, Department of Physiology, A J Institute of Medical Sciences and Research Centre, Mangalore, Karnataka. \\ ${ }^{2}$ Additional Professor, Department of Physiology, K. S. Hegde Medical Academy, Nitte (Deemed to be University), Mangalore, \\ Karnataka, India. \\ 3Professor and HOD, Department of General Medicine, K. S. Hegde Medical Academy, Nitte (Deemed to be University), Mangalore, \\ Karnataka, India. \\ ${ }^{4}$ Professor and HOD, Department of Physiology, K. S. Hegde Medical Academy, Nitte (Deemed to be University), Mangalore, Karnataka, \\ India.
}

\begin{abstract}
BACKGROUND
Type 2 Diabetes Mellitus (T2DM) is a chronic metabolic disorder and a leading cause of premature morbidity and mortality. This metabolic syndrome is associated with risk factors; such as visceral adiposity, dyslipidaemia, hyperglycaemia and hypertension. We wanted to compare the Metabolic and Cardiovascular parameters in patients with T2DM undergoing different treatment modalities.
\end{abstract}

ABSTRACT

\section{METHODS}

A total of 150 subjects were recruited and were divided into three groups; healthy controls $(n=50)$, diabetics under oral hypoglycaemic drugs $(n=50)$ and diabetics undergoing insulin therapy with oral hypoglycaemic drugs $(n=50)$. Cardiovascular parameters like resting heart rate, blood pressure and heart rate variability were evaluated. Metabolic profiles included were waist-hip ratio, fat percent and lipid profile. Cardiovascular and metabolic parameters were compared between three groups using One Way ANOVA with Tukey's post-hoc test.

\section{RESULTS}

Statistical analysis showed that metabolic and cardiovascular profiles are significantly different between the three study groups. Further, T2DM patients with insulin therapy exhibited higher levels of dyslipidaemia and cardiovascular autonomic imbalance compared to that of patients without insulin therapy. However, patients with insulin therapy had poor glycaemic control as assessed by levels of glycated haemoglobin compared to patients only on oral hypoglycaemic agents and control groups.

\section{CONCLUSIONS}

Findings of the study suggest that T2DM patients undergoing insulin therapy exhibit significantly higher levels of dyslipidemia and cardio-vascular autonomic imbalance when compared to age-matched T2DM patients under oral hypoglycaemic drugs. Altered metabolic and cardiovascular profile observed among patients on insulin therapy could be due to their poor glycaemic control. Thus, the study concludes that tightness of glycaemic control is essential to avoid premature morbidity and mortality.

\section{KEY WORDS}

T2DM, Glycated Haemoglobin, Anthropometric Measures, HRV, Lipid Profile

HOW TO CITE THIS ARTICLE: Suvarna SHI, Moodithaya S, Sharma R, et al. Metabolic and cardiovascular profile in type 2 diabetes mellitus patients undergoing different treatment modalities. J. Evolution Med. Dent. Sci. 2019;8(24):1921-1925, DOI: $10.14260 /$ jemds/2019/422

\section{BACKGROUND}

Type 2 Diabetes Mellitus (T2DM) is a metabolic disorder characterized by hyperglycaemia, either due to reduced insulin secretion or increased insulin resistance. It is also associated with impaired carbohydrate, protein and lipid metabolism.[1] Altered lipid metabolism exhibits elevated serum cholesterol, LDL, triglycerides and decreased levels of

'Financial or Other Competing Interest': None.

Submission 16-04-2019, Peer Review 03-06-2019,

Acceptance 10-06-2019, Published 17-06-2019.

Corresponding Author:

Shailaja Moodithaya,

Additional Professor,

Department of Physiology,

K. S. Hedge Medical Academy,

Nitte (Deemed to be University), Mangalore,

Karnataka, India.

E-mail: shailaja.moodithaya@nitte.edu.in

DOI: $10.14260 /$ jemds/2019/422
HDL. These dyslipidaemia features of T2DM are associated with increased risk of cardiovascular disease.[2] Hyperglycaemia in diabetes leads to accumulation of advanced glycation end products (AGE's) and free radicals in the tissues. AGE's formed by the nonenzymatic glycation of proteins, lipids, and nucleic acids promote atherosclerosis, diabetic micro and macro vascular complications. ${ }^{[3]}$ Chronic hyperglycaemia induced production of harmful metabolites is responsible for neuronal damage. Excess free radicals in the body influence the signal transmission in the neurons innervating the heart leading to autonomic dysfunction. ${ }^{[4]}$ Cardiac autonomic dysregulation increases the risk of cardiovascular accidents (CVD).[5] Thus poor glycaemic control plays a vital role in premature atherosclerotic changes, endothelial dysfunction, hypertension and mortality due to cardiovascular morbidity.[6] These micro and macro vascular complications reduce the life expectancy and quality of life in diabetic patients. 
Glycated Haemoglobin (HbA1c) is a trusted standard for monitoring glycaemic control and predicting complications.[7] HbA1c of $7 \%$ is the suggested glycaemic target for T2DM patients. Achieving a near normal glycaemic control will lower the risk of diabetic complications. ${ }^{[8]}$ The above suggested glycaemic target can be achieved by life style modifications or by treatment modalities like oral hypoglycaemic drug therapy and exogenous insulin therapy.[9] Though T2DM is not an insulin dependent disorder, progressive decline in beta cell mass and function or increased insulin receptor resistance will make the diabetic patients to gradually depend on insulin therapy for satisfactory glycaemic control.[10]

The results of our previous study exhibited significant differences in metabolic and cardiovascular parameters of T2DM patients when compared with their age and gender matched healthy controls.[11] The present study was undertaken to compare the Metabolic and Cardiovascular profile in patients with T2DM undergoing different treatment modalities for achieving glycaemic control.

\section{METHODS}

The study was designed as comparative cross-sectional study and comprising of 150 subjects. This study is part of ongoing main study; therefore, data provided here is based on convenient sample size. 100 T2DM patients undergoing regular treatment in Department of Medicine, K. S. Hegde Medical Academy were selected for this study. These patients were divided into two groups based on their treatment modalities. Diabetic subjects treated with Oral Hypoglycaemic Drug, Metformin alone belonged to OHD or Group I $(n=50)$ and patients treated with Insulin injections along with Metformin were considered as OHDI or Group II $(n=50)$. Group III $(n=50)$ included healthy volunteers recruited from the staff of K. S. Hegde Medical College, Deralakatte, Mangalore, Karnataka, India. Participants were selected on the inclusion criteria of age between $40-60$ years and T2DM patients who were under Oral Hypoglycaemic medication or insulin therapy for at least one year. Patients with diabetic complications, T1DM, and those with cold, fever and allergy during recruitment were also excluded from the study.

\section{Experimental Procedure}

After obtaining the institutional ethics committee approval, detailed study protocol was explained to the subjects and informed consent was taken from each participant. History taking included the family history, personal history and detailed medical history of the subject which also included duration of the disorder and mode of treatment for T2DM.

\section{Metabolic Parameters}

Assessment of metabolic parameters included the evaluation of anthropometric and biochemical measurements. Anthropometric measures recorded were height, weight, waist and hip circumference, skin fold thickness of biceps, triceps, sub scapular and supra iliac sites using standard techniques. Standard equations were used to calculate BMI, waist hip ratio and fat percent.[12]

For biochemical analysis, participants were advised to observe 12 hours of overnight fast and the next morning $5 \mathrm{ml}$ of blood sample was obtained from each subject in fluoride and EDTA vials under aseptic precautions. The sample was analysed for Fasting Blood Sugar (FBS) by the glucose oxidase- peroxidase method, Glycosylated Hemoglobin levels (HbA1c) was estimated by Nephelometric method, in Fasting lipid profile; Total cholesterol was estimated by cholesterol oxidase method, Triglycerides by GPO- POD method, HDL by HDL -C-direct and LDL by Friedwald Equation.[13]

\section{RESULTS}

\begin{tabular}{|c|c|c|c|c|c|}
\hline Variables & $\begin{array}{c}\text { Group I } \\
(\mathbf{n = 5 5})\end{array}$ & $\begin{array}{c}\text { Group II } \\
(\mathbf{n}=\mathbf{5 5})\end{array}$ & $\begin{array}{c}\text { Group III } \\
(\mathbf{n = 5 5})\end{array}$ & $\begin{array}{c}\mathbf{F} \\
\text { value }\end{array}$ & p Value \\
\hline Age $(\mathrm{Yrs})$. & $53.57 \pm 8.76$ & $53.66 \pm 6.94$ & $52.46 \pm 5.81$ & 0.48 & 0.62 \\
\hline $\mathrm{BMI}\left(\mathrm{kg} / \mathrm{mt}^{2}\right)$ & $24.02 \pm 3.57$ & $24.53 \pm 4.32$ & $25.04 \pm 3.99$ & 0.99 & 0.37 \\
\hline $\mathrm{W} / \mathrm{H}$ ratio & $\mathbf{0 . 8 6} \pm \mathbf{0 . 0 5} *$ & $\mathbf{0 . 8 8} \pm \mathbf{0 . 0 4} *$ & $\mathbf{0 . 8 1} \pm \mathbf{0 . 0 8}$ & $\mathbf{1 0 . 8 7}$ & $<\mathbf{0 . 0 0 1}$ \\
\hline $\mathrm{Fat}(\%)$ & $29.25 \pm 8.46$ & $28.96 \pm 6.35$ & $32.00 \pm 7.70$ & 2.74 & 0.06 \\
\hline Table 1. Comparison of Metabolic (Anthropometric) Parameters \\
Between 3 Groups \\
\hline
\end{tabular}

- Data expressed as Mean \pm SD.

- Comparison was done using one-way ANOVA \& significance between the groups was assessed by Tukey's Post-hoc test.

- $\quad$ P value $<0.05$ considered statistically significant.

- $\quad$ p value < 0.01 considered statistically highly significant.

- BMI- Body Mass Index, W/H ratio- waist hip ratio, FMfat mass.

- Group I- T2DM patients treated with oral hypoglycaemic drug (OHD).

- Group II - T2DM patients treated with Insulin and oral hypoglycaemic drug (OHDI).

- Group III- Healthy controls.

- * - Significantly different from Control group.

- $\quad$ - Significantly different from OHD group.

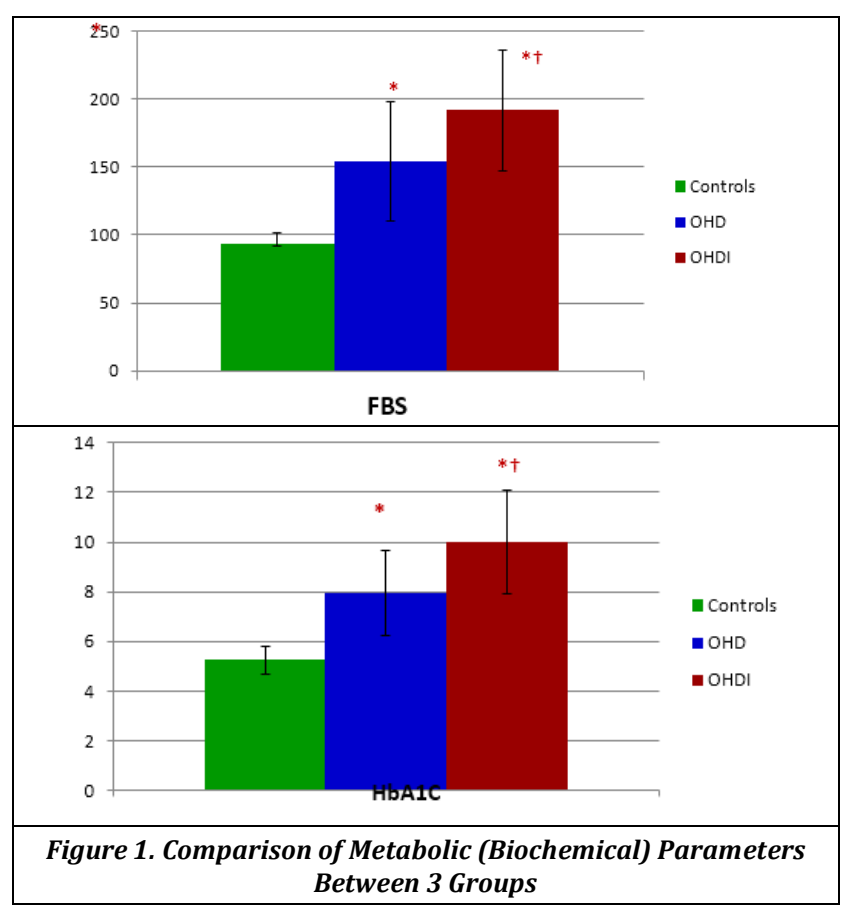

- Data expressed as Mean \pm SD.

- Comparison was done using one-way ANOVA \& significance between the groups was assessed by Tukey's Post-hoc test.

- FBS- Fasting Blood Sugar, HbA1c- Glycosylated haemoglobin.

- *-Significantly different from Control group.

- †-Significantly different from OHD group. 


\begin{tabular}{|c|c|c|c|c|c|}
\hline Variables & $\begin{array}{l}\text { Group I } \\
(n=55)\end{array}$ & $\begin{array}{l}\text { Group II } \\
(n=55)\end{array}$ & $\begin{array}{c}\text { Group III } \\
(n=55)\end{array}$ & F value & p-Value \\
\hline $\begin{array}{l}\text { Total Cholesterol } \\
(\mathrm{mg} / \mathrm{dl})\end{array}$ & $\begin{array}{c}223.24 \pm \\
36.42\end{array}$ & $\begin{array}{c}239.88 \pm \\
31.17\end{array}$ & $\begin{array}{c}186.30 \pm \\
35.61\end{array}$ & 35.31 & $<0.001$ \\
\hline $\begin{array}{c}\text { Triglycerides } \\
(\mathrm{mg} / \mathrm{dl})\end{array}$ & $\begin{array}{c}175.64+ \\
57.20^{*}\end{array}$ & $\begin{array}{l}195.82 \pm \\
71.55^{*}\end{array}$ & $\begin{array}{c}119.64 \pm \\
37.90\end{array}$ & 23.82 & $<0.001$ \\
\hline LDL(mg/dl) & $\begin{array}{c}148.88 \pm \\
31.34^{*}\end{array}$ & $\begin{array}{l}156.56 \pm \\
28.13^{*} \dagger\end{array}$ & $\begin{array}{c}114.84 \pm \\
34.62\end{array}$ & 25.29 & $<0.001$ \\
\hline HDL(mg/dl) & $\begin{array}{c}42.98 \pm \\
7.59^{*}\end{array}$ & $\begin{array}{l}38.41 \pm \\
7.88^{*}+\end{array}$ & $\begin{array}{c}49.87 \pm \\
11.77\end{array}$ & 15.83 & $<0.001$ \\
\hline LDL/HDL & $\begin{array}{l}3.55 \pm \\
0.99 *\end{array}$ & $\begin{array}{l}4.11 \pm \\
1.06^{*} \dagger\end{array}$ & $2.56 \pm 0.94$ & 30.75 & $<0.001$ \\
\hline $\begin{array}{c}\text { Total } \\
\text { Cholesterol/ HDL }\end{array}$ & $\begin{array}{l}5.40 \pm \\
1.36^{*}\end{array}$ & $\begin{array}{l}6.27 \pm \\
1.24 * \dagger\end{array}$ & $\begin{array}{l}4.13 \pm \\
1.03\end{array}$ & 37.13 & $<0.001$ \\
\hline
\end{tabular}

- Data expressed as Mean \pm SD.

- Comparison was done using one-way ANOVA \& significance between the groups was assessed by Tukey's Post-hoc test.

- P value $<0.05$ considered statistically significant.

- $\quad$ v value $<0.01$ considered statistically highly significant.

- LDL- low density cholesterol, HDL- High Density Cholesterol.

- $\quad$ Group I- T2DM patients treated with oral hypoglycaemic drug (OHD).

- $\quad$ Group II - T2DM patients treated with Insulin and oral hypoglycaemic drug (OHDI).

- Group III- Healthy controls.

- *-Significantly different from Control group.

- †-Significantly different from OHD group.

\begin{tabular}{|c|c|c|c|c|c|}
\hline Variables & $\begin{array}{c}\text { Group I } \\
(\mathbf{n}=\mathbf{5 5})\end{array}$ & $\begin{array}{c}\text { Group II } \\
(\mathbf{n}=\mathbf{5 5})\end{array}$ & $\begin{array}{c}\text { Group III } \\
(\mathbf{n = 5 5})\end{array}$ & $\begin{array}{c}\text { F } \\
\text { value }\end{array}$ & $\mathbf{p}$ Value \\
\hline $\mathrm{SBP}(\mathrm{mmHg})$ & $\begin{array}{c}131.05 \pm \\
18.70^{*}\end{array}$ & $\begin{array}{c}137.80 \pm \\
11.65^{*} \dagger\end{array}$ & $\begin{array}{c}119.73 \pm \\
9.20\end{array}$ & 36.93 & $<0.001$ \\
\hline $\mathrm{DBP}(\mathrm{mmHg})$ & $\begin{array}{c}82.90 \pm \\
6.03^{*}\end{array}$ & $\begin{array}{c}83.40 \pm \\
5.57^{*} \dagger\end{array}$ & $\begin{array}{c}77.26 \pm \\
4.92\end{array}$ & 33.78 & $<0.001$ \\
\hline $\mathrm{MBP}(\mathrm{mmHg})$ & $\begin{array}{c}98.95 \pm \\
8.17^{*}\end{array}$ & $\begin{array}{c}101.53 \pm \\
6.37^{*} \dagger\end{array}$ & $\begin{array}{c}91.42 \pm \\
5.94\end{array}$ & 49.37 & $<0.001$ \\
\hline $\begin{array}{c}\text { Resting Heart Rate } \\
\text { (bts/min) }\end{array}$ & $\begin{array}{c}74.89 \pm \\
11.18^{*}\end{array}$ & $\begin{array}{c}80.65 \pm \\
10.80^{*} \dagger\end{array}$ & $\begin{array}{c}69.46 \pm \\
9.52\end{array}$ & 15.32 & $<0.001$ \\
\hline $\begin{array}{c}\text { Duration of } \\
\text { Diabetes (years) }\end{array}$ & $\begin{array}{c}6.50 \pm \\
4.0\end{array}$ & $7.8 \pm 4.63$ & & 0.23 & 0.62 \\
\hline
\end{tabular}

Table 3. Comparison of Cardiovascular Parameters Between 3 Groups

- $\quad$ Data expressed as Mean $\pm \mathrm{SD}$

- Comparison was done using one-way ANOVA \& significance between the groups was assessed by Tukey's Post-hoc test.

- P value $<0.05$ considered statistically significant.

- p value $<0.01$ considered statistically highly significant.

- SBP- Systolic Blood Pressure, DBP- Diastolic Blood Pressure, MBP- Mean arterial Blood Pressure.

- $\quad$ Group I- T2DM patients treated with oral hypoglycaemic drug (OHD).

- Group II - T2DM patients treated with Insulin and oral hypoglycaemic drug (OHDI).

- Group III- Healthy controls.

- *-Significantly different from Control group.

- $\quad \dagger$-Significantly different from OHD group.

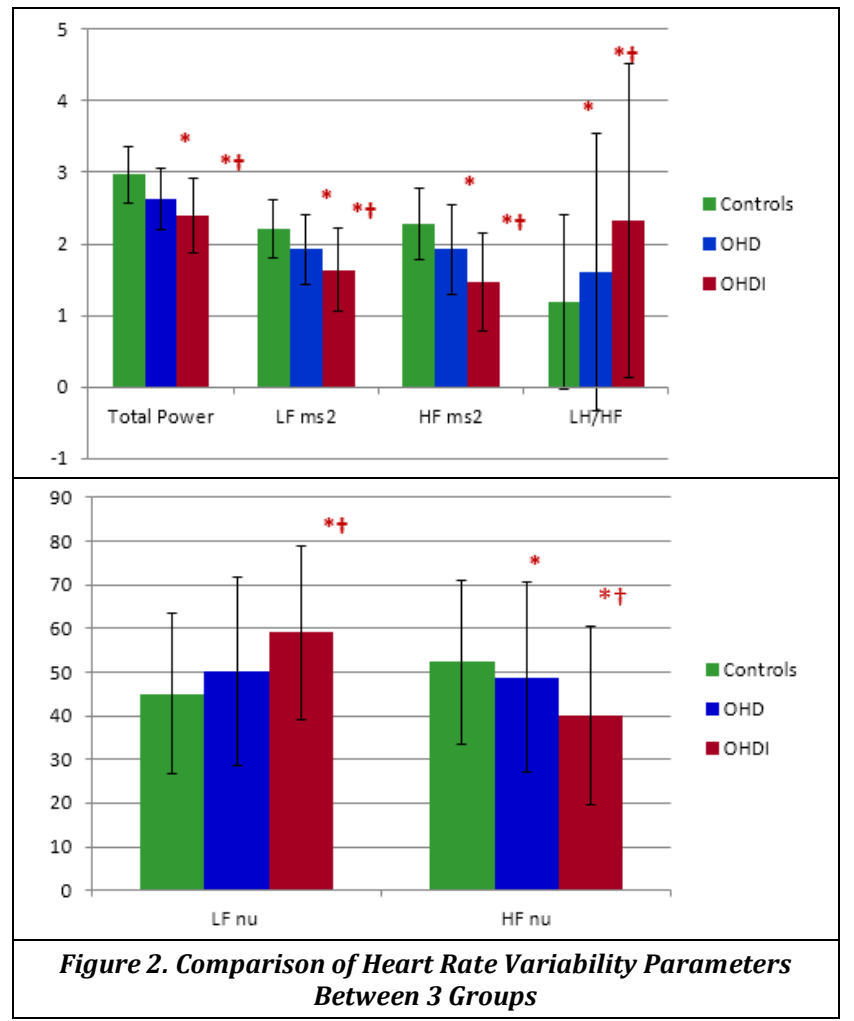

- Log transformed data expressed as Mean \pm SD.

- Comparison was done using one-way ANOVA \& significance between the groups was assessed by Tukey's Post-hoc test.

- $\quad$ TP- Total Power, LF(ab)- Low Frequency absolute, HF (ab)- High Frequency absolute, LF(nu)- Low Frequency normalized units, HF(ab)- High Frequency normalized units.

- * Significantly different from control group.

- † Significantly different from OHD group.

\section{Cardio-Vascular Parameters}

Assessment of cardiovascular parameters included the evaluation of resting heart rate, blood pressure and heart rate variability.

Heart rate variability was measured using a data acquisition unit; Power Lab, AD Instruments, Australia. It is a computerized 4- channel acquisition system. Lead II ECG was recorded with a sampling frequency of $1000 \mathrm{HZ}$, with subject in supine position but awake and resting for 5 minutes. From the obtained ECG recording frequency domain parameters namely Total Power (TP), High Frequency (HF - 0.15 to 0.4 $\mathrm{Hz}$ ) reflecting parasympathetic tone, Low Frequency (LF $0.04-0.15 \mathrm{~Hz}$ ) representing both sympathetic and parasympathetic tone, Very Low Frequency (VLF - 0.0033 to $0.04 \mathrm{~Hz}$ ) reflecting thermoregulatory mechanisms and LF/HF Ratio an indicator of sympatho vagal balance were recorded.[14]

\section{Statistical Analysis}

Statistical analysis was performed with Statistical software IBM SPSS Version 17.0. One-way ANOVA was performed to compare the metabolic and cardiovascular variables between three groups; further Tukey's Post-hoc test was done for multiple comparisons with in the groups. P value $<0.05$ was considered statistically significant and $p$ value $<0.001$ was considered statistically highly significant. 


\section{DISCUSSION}

T2DM can be treated by different methods ranging from life style modifications to oral hypoglycaemic agents and Insulin injections. Metformin is widely preferred first line of treatment to control blood sugar in T2DM. However treatment of T2DM can be intensified by Insulin injection therapy if optimal glycaemic control cannot be achieved by life style modifications and oral hypoglycaemic agents alone.

The current study compared the metabolic and cardiovascular parameters of T2DM patients undergoing different treatment modalities. Cardiovascular parameters like resting heart rate, blood pressure and heart rate variability were evaluated. Metabolic profiles included were the waist-hip ratio, fat percent and lipid profile. i) Patients on metformin, ii) patients on insulin along with metformin iii) age and gender matched controls were included as three study groups.

Findings of this study demonstrated that T2DM patients on a combined therapy of insulin injections and oral hypoglycaemic drugs had significantly higher levels of dyslipidaemia, hypertension and autonomic dysfunction when compared to T2DM patients treated with oral hypoglycaemic drugs alone in spite of having same mean age and duration of the disorder.

Metabolic indices assessed by anthropometric measures are presented in Table 1. Findings indicate that though the BMI, fat percent did not show any significant difference between the groups the waist hip ratio (WHR) was significantly higher among diabetic groups both with and without insulin compared to that of healthy controls indicating greater proportion of abdominal fat in diabetics. Further, WHR was significantly higher in group with insulin therapy compared to that of without insulin therapy. Studies done by Mokdad etal and Motewar Sapana S et al also showed that significant association of T2DM with central obesity.[15,16] Central fat deposition also called "Android distribution" is a major risk factor for cardiovascular risk than the "Gynoid distribution" (Peripheral fat).[17]

Analysis of variance showed that total cholesterol, triglycerides, LDL levels are significantly higher and HDL level is significantly reduced in diabetic patients with insulin therapy when compared to age matched diabetic patients treated with OHA. (Table 2). A surrogate marker of insulin resistance, TG/HDL ratio was significantly higher in T2DM patients of our study, with marked raise in patients undergoing insulin therapy. This result is in agreement with the findings of Framingham Heart Study. ${ }^{[18]}$ Insulin affects the liver apolipoprotein production. It regulates the enzymatic activity of lipoprotein lipase and Cholesterol ester transport protein. All these factors can be the cause of dyslipidaemia in Diabetes mellitus.[13]

The analysis of cardiovascular parameters showed that (Table 3, ) Resting Heart Rate and Blood Pressure parameters (SBP, DBP, PP, MBP) are significantly higher in T2DM patients with both treatment modalities when compared to age matched healthy subjects. Further, the same parameters are significantly higher in patients with combined therapy when compared to their gender and duration of the disorder matched patients with only oral hypoglycaemic therapy. This result is in par with the study done by Guido et al and Sowers J et al.[19,20]

Cardiac autonomic indices were measured by frequency domain analysis of short term HRV. Findings of this study (Fig. 2) revealed that diabetes mellitus is associated with significant reduction in HRV when compared to age matched healthy counterparts and post-hoc tests revealed that autonomic dysfunction is significantly higher in T2DM patients with insulin therapy when compared to those with oral drugs alone.

Significant reduction in Total Power observed in T2DM patients of combined treatment group indicates a prominent reduction in autonomic input to heart. HRV marker of parasympathetic modulation (HF power) is significantly reduced and LF power in absolute units, an indicator of both sympathetic and parasympathetic activity is also significantly reduced in diabetic groups especially in patients taking Insulin with OHA. LF/HF ratio is a marker of sympatho vagal activity, is significantly increased in diabetic patients undergoing insulin therapy. This result is consistent with the observations of Istenes et al and Kudat $\mathrm{H}$ et al[21,22] and also with the findings of studies like Framingham study and Hoorn study[23,24] which stated that there is an increase in Heart rate and overall decrease in HRV with an increase in $\mathrm{LF} / \mathrm{HF}$ in T2DM patients indicating more parasympathetic damage than sympathetic.

Earlier studies compared the metabolic and cardiovascular parameters between normal and T2DM patients independently.[16,21] But in our study, we evaluated above parameters in same study population including T2DM patients undergoing different treatment modalities.

The present study demonstrated significant differences in the metabolic and cardiovascular profile of T2DM patients of different treatment modalities in spite of the same mean age and duration of the disorder. Further, patients on insulin combined therapy in our study exhibited significantly higher FBS \& HbA1c (Fig. 1) when compared to patients of OHD group. This finding indicates that in spite of insulin therapy, these patients had poor glycaemic control.

Insulin resistance, hyperinsulinemia cycle could be the reason for dyslipidaemia in insulin treated T2DM patients of our study. Insulin regulates the enzymatic activity of lipoprotein lipase and cholesterol ester transport proteins. Thus, a high insulin resistant state promotes hepatic VLDL production and inhibits lipoprotein lipase activity contributing to Hypertriglyceridemia.[25]

Study has shown that hyperglycaemia induced oxidative stress and chronic low grade inflammation in T2DM leads to increased production of Angiotensinogen and Angiotensin II in adipose tissues and contributes to cardiovascular dysfunction.[26] Similarly Studies have also stated that hyper insulinemia increases sodium reabsorption in the distal convoluted part of kidney by increasing the expression of epithelial sodium channels subsequently resulting in plasma expansion and hypertension.[19,27] Further, hyperglycaemia has deleterious effect on vagal activity and thus vagal denervation resulting in sympathetic dominance.[28] Therefore, study concludes that the higher levels of dyslipidaemia and cardiac autonomic imbalance observed in patients with insulin therapy in this study could be attributed to hyperinsulinemia or poor glycaemic control.

\section{CONCLUSIONS}

Findings of the study suggest that T2DM patients undergoing insulin therapy exhibit significantly higher levels of 
dyslipidemia and cardio-vascular autonomic imbalance when compared to age-matched T2DM patients under oral hypoglycaemic drugs. Altered metabolic and cardiovascular profile observed among patients on insulin therapy could be due to their poor glycaemic control. Thus, the study concludes that tightness of glycaemic control is essential to avoid premature morbidity and mortality.

\section{ACKNOWLEDGEMENTS}

We sincerely thank P S Prakash, Dean, K. S. Hegde Medical Academy, NITTE (Deemed to be) University for his cooperation in recruitment of patients and providing us the facilities required for data collection. We are also grateful to Professor K. S. Das, Head of Department Physiology, A J Institute of Medical Sciences for his cooperation and support for the study.

\section{REFERENCES}

[1] Reaven GM. Role of insulin resistance in human disease (syndrome X): an expanded definition. Annu Rev Med 1993;44:121-31.

[2] Vergès B. New insight into the pathophysiology of lipid abnormalities in type 2 diabetes. Diabetes Metab 2005;31(5):429-39.

[3] Glenn JV, Stitt AW. The role of advanced glycation end products in retinal ageing and disease. Biochim Biophys Acta 2009;1790(10):1109-16.

[4] Vinik AI, Ziegler D. Diabetic cardiovascular autonomic neuropathy. Circulation 2007;115(3):387-97.

[5] Freccero C, Svensson H, Bornmyr S, et al. Sympathetic and parasympathetic neuropathy are frequent in both type 1 and type 2 diabetic patients. Diabetes Care 2004;27(12):2936-41.

[6] Kolhar U, Priyanka P. Study of serum lipid profile in type 2 diabetes mellitus patients and its association with diabetic nephropathy. Int J Adv Med 2017;4(6):1513-6.

[7] Cohen RM, Smith EP. Frequency of HbA1c discordance in estimating blood glucose control. Curr Opin Clin Nutr Metab Care 2008;11(4):512-7.

[8] Dasanayake DGBMS. Glycosylated Hemoglobin (HbA1C). Manual of Diabetes mellitus. January 31, 2009.

[9] Wu Y, Ding Y, Tanaka Y, et al. Risk factors contributing to type 2 diabetes and recent advances in the treatment and prevention. Int J Med Sci 2014;11(11):1185-200.

[10] Turner RC, Cull CA, Frighi V, et al. Glycaemic control with diet, sulfonylurea, metformin, or insulin in patients with type 2 diabetes mellitus: progressive requirement for multiple therapies. UK Prospective Diabetes Study (UKPDS) Group. JAMA 1999;281(21):2005-12.

[11] Suvarna HIS, Moodithaya S, Sharma R. Metabolic and cardiovascular ageing indices in relation to glycated haemoglobin in healthy and diabetic subjects. Current Ageing Science 2017;10(3)201-10.

[12] Durmin JVGA, Womersely J. Body fat assessed from total body density and its estimation from skin fold thickness measurements on 481 men and women aged from 16 - 72 years. Br J Nutr 1974;32(1):77-97.
[13] Friedewald WT, Levy RI, Fredrickson DS. Estimation of the concentration of low-density lipoprotein cholesterol in plasma, without use of the preparative ultracentrifuge. Clin Chem 1972;18(6):499-502.

[14] Task Force of European Society of Cardiology and the North American Society of Pacing and Electrophysiology. Heart rate variability: standards of measurement, physiological interpretation and clinical use. Circulation 1996;93(5):1043-65.

[15] Mokdad AH, Ford ES, Bowman BA, et al. Prevalence of obesity, diabetes and obesity-related health risk factors. 2001. JAMA 2003;289(1):76-9.

[16] Motewar SS, Bachewar Narendra $P$, et al. A comparative study of anthropometric parameters and lipid profile in type 2 diabetes mellitus. International Journal of Medical and Applied Sciences 2014;3(3).

[17] Wang J, Thornton JC, Kolesnik S, et al. Anthropometry in body composition. An overview. Ann N Y Acad Sci 2000;904:317-26.

[18] Kannel WB. Lipids, diabetes and coronary heart disease: Insights from the Framingham Study. Am Heart J 1985;110(5):1100-7.

[19] Lastra G, Syed S, Kurukulasuriya LR, et al. Type 2 diabetes mellitus and hypertension: an update. Endocrinol Metab Clin North Am 2014;43(1):103-22.

[20] Sowers JR, Epstein M, Frohlich ED. Diabetes, hypertension and cardiovascular disease: an update. J Hypertens 2001;37(4):1053-9.

[21] Istenes I, Körei AE, Putz Z, et al. Heart rate variability is severely impaired among type 2 diabetic patients with hypertension. Diabetes Metab Res Rev 2014;30(4):305-12.

[22] Kudat $H$, Akkaya $V$, Sozen $A B$, et al. Heart rate variability in diabetes patients. J Int Med Res 2006;34(3):291-6.

[23] Singh JP, Larson MG, O'Donnell CJ, et al. Association of hyperglycaemia with reduced heart rate variability (The Framingham Heart Study). Am J Cardiol 2000;86(3):309-12.

[24] Gerritsen J, Dekker JM, TenVoorde BJ, et al. Glucose tolerance and other determinants of cardiovascular autonomic function: the Hoorn study. Diabetologia 2000;43(5):561-70.

[25] Li N, Fu J, Koonen DP, et al. Are hypertriglyceridemia and low HDL causal factors in the development of insulin resistance? Atherosclerosis 2014;233(1):1308.

[26] Massiera F, Bloch-Faure M, Ceiler D, et al. Adipose angiotensinogen is involved in adipose tissue growth and blood pressure regulation. FASEB J 2001;15(14):2727-9.

[27] Song J, Hu X, Riazi S, et al. Regulation of blood pressure, the epithelial sodium channel (ENaC), and other key renal sodium transporters by chronic insulin infusion in rats. Am J Physiol Renal Physiol 2006;290(5):F1055-64.

[28] Pop-Busui R, Kirkwood I, Schmid H, et al. Sympathetic dysfunction in type 1 diabetes: association with impaired myocardial blood flow reserve and diastolic dysfunction. J Am Coll Cardiol 2004;44(12):2368-74. 